\title{
Natural outbreak of Marek's disease in indigenous chicken and Japanese quail (Coturnix coturnix japonica) in Jos, Plateau State, Nigeria
}

\author{
Adeyinka Jeremy Adedeji ${ }^{1 *}$, Olatunde Babatunde Akanbi ${ }^{2}$, Pam Dachung Luka ${ }^{1}$ and Paul $\mathrm{Abdu}^{3}$ \\ ${ }^{1}$ National Veterinary Research Institute, Vom, Nigeria \\ ${ }^{2}$ Department of Veterinary Pathology, Faculty of Veterinary Medicine, University of Ilorin, Nigeria \\ ${ }^{3}$ Department of Veterinary Medicine, Faculty of Veterinary Medicine, Ahmadu Bello University Zaria, Nigeria
}

\begin{abstract}
Carcasses of an indigenous adult chicken and Japanese quail from different flocks were presented to a veterinary clinic for postmortem (PM) examination in 2014 in Jos, Plateau State, Nigeria. PM observations revealed cutaneous, hepatic, and splenic tumors in the Indigenous chicken. The quail carcass was emaciated with hepatic tumors. Histopathology revealed severe focally extensive non-encapsulated circumscribed large nodules with pleomorphic population of cells mainly composed of lymphoplasmacytic and mixed neutrophilic polymorphonuclear cells in the chicken. The pleomorphic infiltration of lymphohistioplasmacytic cells mixed with neutrophilic polymorphonuclear cells in the quail was consistent with Marek's disease virus (MDV) infection. Polymerase chain reaction (PCR) was carried out, and the Meq oncogene of the MDV was amplified in the samples collected from the chicken and quail to confirm the presence of the virulent MDV. The samples were also subjected to PCR for detection of MDV Rispens CVI988 vaccine strain which was detected in both chicken and quail samples. The findings in this study represent the first report of confirmatory diagnosis of MD using histopathology in an indigenous chicken and Japanese quail in Nigeria. It is also the first report of the detection of MDV Rispens CVI988 vaccine strain in unvaccinated chicken and quail in Nigeria. Keywords: Indigenous chicken, Japanese quail, Marek’s disease, Nigeria.
\end{abstract}

\section{Introduction}

Marek's disease (MD) is one of the most economically important and devastating diseases of poultry (Hassanin et al., 2013). It was first described by a Hungarian veterinary pathologist Jozsef Marek in the last century (Pastoret, 2004; Biggs and Nair, 2012). MD is caused by MD virus (MDV) which is a highly infectious, cell associated, and potent oncogenic herpes virus (Nair and Fadly, 2013). MDV belongs to the family Herpesviridae, subfamily Alphaherpesvirinae, and genus Mardivirus (Davison, 2010; Hassanin et al., 2013). The genus Mardivirus has three members that are serologically related but distinct species: Gallid herpesvirus 2 (serotype 1), Gallid herpesvirus 3 (serotype 2), and Meleagrid herpesvirus 1 (Herpesvirus of turkey [HVT], serotype 3) (Gimeno and Pandiri, 2013; Lv et al., 2017). All the virulent or oncogenic strains of MDV belong to serotype 1 (Schat, 2016). Currently, four pathotypes have been identified which include: mild (m) MDV, virulent (v) MDV, very virulent (vv) MDV, and very virulent plus ( $\mathrm{vv}^{+}$) MDV strains (Schat and Nair, 2013). The MDV serotype 2 and 3 are not pathogenic and are used as candidates for the production of vaccines against MD (Schat, 2016). Similarly, a MDV-1 strain known as MDV Rispens CVI998 is the most effective vaccine strain available which can be used alone or in combination with HVT (Diaz, 2014). MDV Rispens CVI988 strain can be differentiated from oncogenic MDV-1 strains by the molecular techniques (Renz et al., 2013; Gimeno et al., 2014). However, one of the fascinating discoveries about MD is that vaccination does not produce sterilizing immunity (Read et al., 2015). That is, MD vaccines protects the hosts from the clinical disease, but neither prevents them from becoming infected, or block transmission or shedding of virulent MDV strains (Gimeno, 2008; Pandey et al., 2016; Reddy et al., 2017). Chickens are the most important natural host for MD, but the disease has been reported in turkeys, Japanese quails, pheasants, owls, ducks, geese, swans, kestrels, crested partridges, and red-crowned cranes (Schat and Nair, 2013; Schock et al., 2016; Lian et al., 2018). Virtually, all the chickens, including game fowl and jungle fowl, are susceptible to MDV infection and tumor development (Schat and Nair, 2013). MD is distributed worldwide and it is of serious economic importance in all the countries with well-developed or developing poultry industry (Biggs and Nair, 2012). Clinical MD is characterized by depression, death, stunting, lethargy, characteristic unilateral paralysis of the legs, and mortality (Gimeno and Pandiri, 2013). Because of the ubiquitous nature of MDV, and hence the presence of the virus in many poultry farms, detection of virus, viral antigens, or nucleic acids in the absence of clinical disease does not confirm the occurrence of MD (Nair, 2018). Clinical signs of MD accompanied 
with tumors in multiple organs, and enlarged peripheral nerves at PM may suffice to make a tentative diagnosis (Nair, 2018). However, confirmatory diagnosis can be done by immunohistochemistry, histopathology and, Polymerase chain reaction (PCR)-based molecular techniques (Zelnik, 2004; Gimeno and Pandiri, 2013). The first case of MD reported in Nigeria was in Ibadan by Hills in 1962 afterward, there were reports in other parts of the country (Nawathe et al., 1978; Olabode et al., 2009; Wakawa et al., 2012). However, documented reports on the status of MD in Nigeria are scanty. Nigeria has a poultry population of 140.7 million chickens with large population of indigenous local chickens (Adene and Oguntade, 2006; FAOSTAT, 2017). The indigenous chickens are kept under extensive management system or free range to roam and scavenge for feed in the most rural households in Nigeria (Ezeokeke and Iyayi, 2015). However, Japanese quail (Coturnix coturnix japonica) production was first introduced into Nigeria in 1992 to augment for the country's animal protein needs (Haruna et al., 1997; Musa et al., 2013). Since then, there has been appreciable increase in the demand for quail meat and eggs by consumers due to the belief that they are medicinal (Musa et al., 2013). Hence, many farmers are venturing into quail production sometimes side by side with chickens. Several poultry diseases have been reported in indigenous local chicken and quails in Nigeria; however, there are no documented studies of MDV infections in local chickens and quails in Nigeria. We report the investigation of MD in an indigenous local chicken and quail in Nigeria.

\section{Materials and Methods}

\section{Case history}

In January, 2014, carcass of an 8-week old Japanese quail was presented to a veterinary clinic in Jos, Plateau State, Nigeria for diagnosis. History revealed that the quail was from a mixed farm with layer chickens. Similarly, in August, 2014, the carcass of a free ranged adult indigenous local chicken (Fig. 1A) was presented to the same veterinary clinic. Previously, the chicken was slaughtered for consumption but after de-feathering, the owner noticed nodular skin lesions which motivated the presentation of the carcass.

Postmortem examination and sample collection Postmortem (PM) examination was carried out on the two carcasses and affected tissue samples were collected for histopathological examination and PCR. Of the samples collected, one part was placed on ice and the other part was placed in $10 \%$ phosphate buffered formalin fixative and transported to the National Veterinary Research Institute (NVRI), Vom Nigeria for laboratory investigation.

\section{Histopathology}

The skin nodules, liver, spleen, and other parenchymatous organs were processed; dehydrated in ethanol $(70 \%-100 \%)$, cleared in xylene as previously described (Akanbi and Taiwo, 2009), and embedded in paraffin. Five-micron thickness of paraffin sections were prepared and labeled appropriately and thereafter, routinely stained with hematoxylin and eosin $(\mathrm{H}$ and E) dyes. For histopathological examination, $100 \times$ and $400 \times$ high-powered field of Carl Zeiss ${ }^{\circledR}$ binocular microscope was used to observe the changes in the tissues.

\section{Polymerase chain reaction}

DNA was extracted from homogenates of the tissue samples collected using QIAamp ${ }^{\circledR}$ DNA mini kit (Qiagen Hilden, Germany) following the manufacturer's instructions. The DNA was initially screened for MDV oncogenic virus using published primers which targets the meq oncogene of MDV (Wozniakowski et al. 2011). The primers are as follows: MDV1-F3 5'-TTCCCTCTTCTGCCCTCC-3'(F), MDV-1B3 TCCTGTTCGGGATCCTCG-3'(R). Samples were considered positive by the amplification of a 200-bps product. Further screening for MDV Rispens CVI988 strain was carried out as described by Renz et al. (2013). The primers sequences are as follows: BCH402 5'-TCGGAGAAGACGCAGGAA-3' (forward), BCH403 5'-GCTCATGACAAGCCAACTGTA-3' (reverse), and it targets the Meq gene of the MDV1 CVI988 Rispens. Samples were considered positive for Rispens CVI988 by amplification of a 152-bps product. The positive controls were virulent MDV Serotype 1 (Md5), MDV serotype 2 (281MI), MDV serotype 3 (HVT FC 126) (all provided by Dr. Aly Fadly of the Avian Diseases and Oncology Laboratory, East Lansing, MI, USA), and MDV1 CVI 988 (MD vaccine, Merial Cryomarex ${ }^{\circledR}$ by Merial SAS France, now Boehringer Ingelheim was used), while nuclease free water was used as negative control. Validations of the protocols was carried out using each of the positive controls to ensure that the primers amplified only the appropriate serotypes or strains as described in the respective publications. The gel electrophoresis carried out and viewed using a Gel Doc ${ }^{\mathrm{TM}} \mathrm{XR}+\mathrm{Gel}$ Documentation System (Biorad ${ }^{\mathrm{TM}}$, California, USA).

\section{Results and Discussion}

PM examination of the indigenous chicken revealed cutaneous lymphomas on the neck (Fig. 1A) and wings (Fig. 1B). Lymphomas were also observed on the intestinal serosa. In the quail, PM examination revealed splenomegaly, lymphoma on the liver (Fig. $1 \mathrm{C}$, arrow), and enlarged spleen with multi focal lymphomas (Fig. 1D). The microscopic changes in the liver of the quail were large pleomorphic infiltration of mainly lymphoplasmacytic inflammatory cells, macrophages, and lymphocytes admixed with neutrophilic polymorphonuclear cells (Fig. 1E). The histopathologic changes observed in the spleen of the local chicken include extensive infiltration by inflammatory cells, such as macrophages and lymphocytes (Fig. 1F). There is severe lymphoid necrosis and depletion (Fig. 1F) with focally extensive 
non-encapsulated circumscribed large nodule. The PCR results revealed that the MDV-1 oncogenic strain was amplified in the samples analyzed, i.e., the liver, skin, and spleen samples of the indigenous chicken and the liver sample of the quail (Fig. 2A), while MDVRispens CVI988 strain was also detected by PCR in the liver, spleen, and skin samples of the indigenous chicken and the liver sample of the quail (Fig. 2B) with positive samples showing single band alongside the positive control at the expected band size.
Indigenous chickens are the integral part of the livelihood of the rural people in Nigeria. They are reported to be hardy and usually allowed to scavenge to fend for themselves. Likewise, the Japanese quails are reported to be resistant to common poultry diseases and multiply very fast. In this report, MD was confirmed in an indigenous chicken and quail based on PM findings, histopathologic changes, and PCR results. Natural cases of MD in Nigerian indigenous chickens has barely been reported in Nigeria although
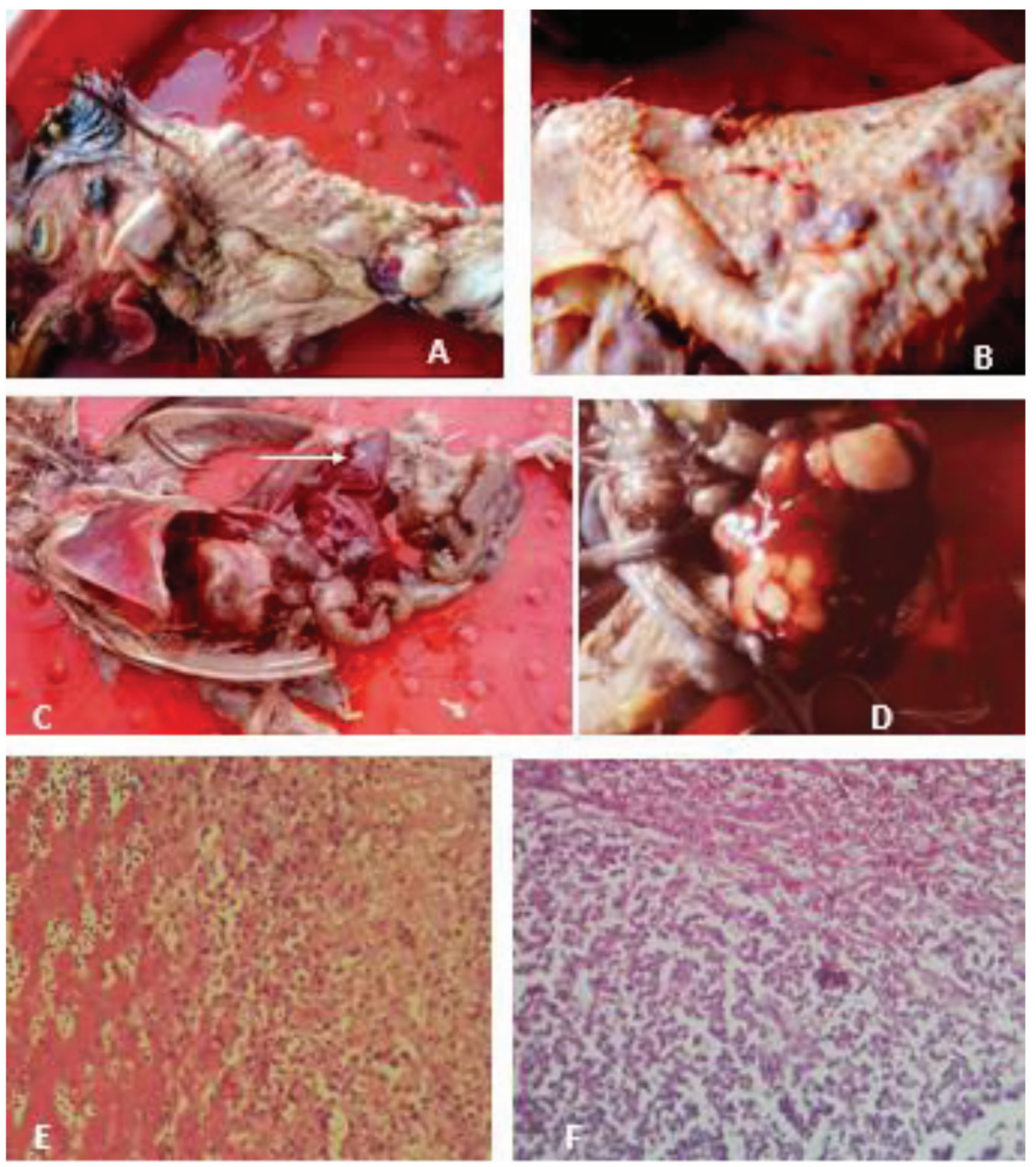

Fig. 1. (A) Neck, indigenous chicken, multifocal nodular cutaneous lymphomas. (B) Wing, indigenous chicken, multifocal nodular cutaneous lymphomas. (C) Whole carcass, Quail with hepatic lymphoma (white arrow). (D) Spleen, indigenous chicken, with multifocal to coalescing splenic lymphoma. (E) Liver, Quail; severe diffuse hepatic coagulation necrosis (left half), sinusoidal expansion and congestion with large pleomorphic infiltration of mainly lymphohistioplasmacytic cells admixed with neutrophilic polymorphonuclear cells (right half) $\mathrm{H} \& \mathrm{E} \times 400$. (F) Spleen, indigenous chicken, nodular border, severe focally extensive non-encapsulated circumscribed large lymphohistioplasmacytic infiltrates admixed with neutrophilic polymorphonuclear cells. There is severe lymphoid necrosis and depletion $(\mathrm{H} \& \mathrm{E} \times 400)$. 
Sani et al. (2017) reported a case in Zaria, however, the technique for the diagnosis of the disease was not stated. Meanwhile, natural outbreaks of MD have been reported in Japanese quail in some countries where these birds are raised commercially (Payne, 2004) but not in Nigeria. Quails diagnosed with MD were observed with lymphomas in various visceral organs and mortality of $10 \%-20 \%$ (Schat and Nair, 2013). In addition, transmission of MDV from chickens to quail has also been documented (Dutton et al., 1973). In this report, the gross pathological lesions observed in the indigenous chicken mainly cutaneous and visceral lymphomas were consistent with the findings in cases of MD although similar lesions are also observed in cases of Avian leucosis (AL) and Reticuloendotheliosis (RE) (Nair and Fadly, 2013). Skin lymphomas are usually seen in dressed carcasses of MD cases as observed by the owner of the indigenous chicken in this report (Gimeno and Pandiri, 2013). However, cutaneous lymphomas are a rarity in AL as compared to in $\mathrm{MD}$, while visceral lymphomas in $\mathrm{AL}$ are soft, smooth, and glistening which appears grayish to creamy white (Zelnik, 2004; Nair and Fadly, 2013). Also comparably, the cutaneous lesions in RE are lymphocytic infiltrates in and around feather follicles and the skin of the head and visceral lymphomas are nodular and firm (Zavala, 2013). Interestingly, bursal lymphomas, which are pathognomonic lesions in the diagnosis of AL and RE (Zavala, 2013), were not observed in this indigenous chicken. Hepatic lymphoma which was observed in the Japanese quail carcass is suggestive of MD. Previous reports by Pradhan et al. (1985) and Imai et al. (1990) described lymphomas in visceral organs of quails confirmed to be cases of MD. These descriptions were similar to the one observed in the quail in this study. The microscopic pathology of the spleen of the chicken and liver of the quail revealed inflammatory cells, such as macrophages and lymphocytes which are characteristic cells observed in MD during histopathological examinations (Gimeno and Pandiri, 2013), whilst the predominant cells usually observed during microscopic examination of
$\mathrm{AL}$ and $\mathrm{RE}$ are uniform, blast-like, pyroninophilic cells with B cell markers (Nair and Fadly, 2013; Zavala, 2013). The histopathologic lesions confirmed MD in the indigenous chicken and Japanese quail. Further laboratory investigation was carried out by analyzing the samples collected from the chicken and quail using PCR. The Meq oncogene of the MDV was amplified in the samples collected from the chicken and quail by PCR which confirms the presence of virulent MDV. Because of the complex and ubiquitous nature of MDV, detection of the virus by PCR alone does not confirm the presence of disease. Albeit, there can be infection with the MDV but no clinical disease. However, in this report, clinical MD was observed in form of tumors (lymphomas) in both the indigenous chicken and quail. The criteria for diagnosis of MD include clinical signs, gross lesions, and at least one laboratory test. In this report, gross lesions and two laboratory tests were used to confirm MD in the chicken and quail. Furthermore, the samples collected were subjected to PCR for detection of MDV Rispens CVI988 vaccine strain and the virus was detected in both the chicken and quail samples. All the primers used by Renz et al. (2013) were synthesized and only CVI988 Rispensspecific PCR primers detected the MDV1 CVI988. Vice-versa, we also used the primers by Wozniakowski et al. (2011) and the MDV1 Rispens/CVI988 vaccine was not detected. Also, the CVI988-specific primer did not detect HVT, MDV2, and positive virulent MDV from archive samples during optimization. Nigeria is one of the countries with increasing prevalence of MD, despite the common use of MDV1 Rispens CVI988 vaccines for vaccination and revaccination of birds against MD (Dunn and Gimeno, 2013).

This finding has implications on the epidemiology of MD in Nigeria, because neither the chicken nor quail were vaccinated using Rispens CVI988. It is likely that the MDV Rispens CVI988 vaccine strain was acquired by the birds from contaminated environment. For the quail, it may be from the flock of commercial chickens kept side by side with the flock of quails. While for the indigenous local chicken, the source is difficult to
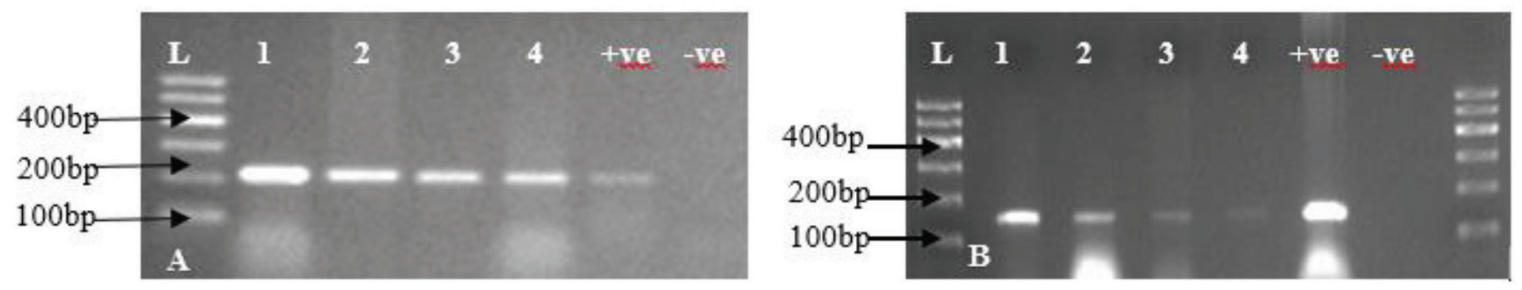

Fig. 2. (A) Agar gel electrophoresis of PCR product of MDV-1 oncogenic strain. Lanes (1-4) are the samples collected from suspected cases of Marek's disease, (1-3) are samples from indigenous chicken, while (4) is the quail sample. The positive samples were amplified at 200 bp fragment. (L): A 100 bp DNA marker (Qiagen $\left.{ }^{\circledR}\right)$. (+ve): Positive control = Md5. (-ve): Negative control = Nuclease free water. (B) Agar gel electrophoresis of PCR product of MDV-1 Rispens CVI988 strain. Lanes (1-4) are samples collected from suspected cases of Marek's disease, (1-3) are samples from indigenous chicken, while (4) is the quail sample. The positive samples were amplified at $152 \mathrm{bp}$ fragment. (L): A $100 \mathrm{bp}$ DNA marker (Qiagen $\left.{ }^{\circledR}\right)$. (+ve): Positive control. (-ve): Negative control. 
ascertain, but one possibility may be chicken litter or manure which is extensively as organic fertilizer for farming in Nigeria. This finding is not entirely surprising since Adedeji et al., (2017) detected HVT using PCR and loop-mediated isothermal amplification assay in local indigenous chicken sample in Nigeria. The husbandry system of poultry farming in some parts of Nigeria particularly, the small holder backyard farms are poor, whereby farmers keep multiple species of birds within the same premises. It is a common practice to keep birds of different ages and free roaming indigenous local chickens in the same premises. Interestingly, Ralapanawe et al. (2016) reported the detection of Rispens CVI988 in unvaccinated chickens in Australia attributed to the natural spread of the MDV Rispens/ CVI988 virus to unvaccinated flocks. In fact in the same study, it was reported that virulent MDV were detected in co-infections with MDV Rispens/ CVI988 virus. One of the short coming of MD vaccines is that they do not provide sterilizing immunity and vaccinated chickens still support replication and shedding of both vaccine and virulent field MD viruses (Reddy et al., 2017).

\section{Conclusion}

This study confirms MD in an indigenous chicken and quail by gross lesions, histopathological examinations, and PCR results. The findings in this study represent the first report of confirmatory diagnosis of MD using histopathology in an indigenous chicken and Japanese quail in Nigeria. It is also the first report of detection of MDV Rispens/CVI988 vaccine strain in unvaccinated chicken and quail in Nigeria. These results add to previous evidence that the MD is endemic in Nigeria. Improving biosecurity and vaccination will mitigate the economic losses associated with the disease.

\section{References}

Adene, D.F. and Oguntade, A.E. 2006. The structure and importance of the commercial and village based poultry industry in Nigeria. FAO consultancy report. Available via http://www.fao.org/docs/ eims/upload//214281/poultrysector_nga_en.pdf (Accessed 15 July 2018).

Akanbi, B.O. and Taiwo, V. 2009. Comparative pathology of the caeca of Anticoccidial immunized chicks infected with a Nigerian isolate and Houghton strain of Eimeria tenella. J. Comp. Pathol. 141(4), 278.

Biggs, P.M. and Nair, V. 2012. The long view: 40 years of Marek's disease research and Avian Pathology. Avian Pathol. 41(1), 3-9.

Davison, A.J. 2010. Herpesvirus systematic. Vet. Microbiol. 143, 52-69.

Diaz, F.J.T. 2014. Marek's disease. In Vaccination of poultry. Eds., Diaz, F.J.T., Martinez, C.G., van den Berg, T., Pena, S.T. and Hauck, R. Zaragoza, Spain: Groupo Asis Biomedia Zaragoza, pp: 3-8.
Dunn, J.R. and Gimeno, I.M. 2013. Current status of Marek's disease in the United States and worldwide based on a questionnaire survey. Avian Dis. 57, 483-490.

Dutton, R.L., Kenzy, S.G. and Becker, W.A. 1973. Marek's disease in the Japanese quail (Coturnix coturnix japonica). Poult. Sci. 52, 139-143.

Ezeokeke, C.T. and Iyayi, E.A. 2015. Production, population and improvement of the local fowl of Southern Nigeria ecotype. Afr. J. Agric. Res. 10(9), 944-955.

FAOSTAT. 2017. Available via http://www.fao.org/ faostat/en/\#data/QA (Accessed 18 August 2018).

Gimeno, I.M. 2008. Marek's disease vaccines: a solution for today but a worry for tomorrow? Vaccine 26, C31-C41.

Gimeno, I.M. and Pandiri, A.R. 2013. Virus-induced immunosuppression: Marek's disease virus infection and associated syndromes. In Immunosuppresive diseases of poultry. Ed., Gimeno, I.M. Zaragoza, Spain: Servet-Group Asis, pp: 124-152.

Gimeno, I.M., Dunn, J.R., Cortes, A.L., El-Gohary, A. and Silva, R.F. 2014. Detection and differentiation of CVI988 (Rispens Vaccine) from other serotype 1 Marek's disease viruses. Avian Dis. 58, 232-243.

Hassanin, O., Abdallah, F. and El-Araby, I.M. 2013. Molecular characterization and phylogenetic analysis of Marek's disease virus from clinical cases of Marek's disease in Egypt. Avian Dis. 57, 555-561.

Haruna, E.S., Musa, U., Lombin, L.H., Tat, P.B., Shamaki, P.D., Okewole, P.A. and Molokwu, J.U. 1997. Introduction of quail production in Nigeria. Nig. Vet. J. 18, 104-107.

Imai, K., Yuasa, N., Kobayashp, S., Nakamura, K., Tsukamoto, K. and Hihara, H. 1990. Isolation of Marek's disease virus from Japanese quail with lymphoproliferative disease. Avian Pathol. 19(1), 119-129.

Lian, X., Ming, X., Xu, J., Cheng, W., Zhang, X., Chen, H., Ding, C., Jung, Y. and Qian, Y. 2018. First molecular detection and characterization of Marek's disease virus in red crowned cranes (Grus japonensis): a case report. BMC Vet. Res. 14(1), 122; doi:10.1186/s12917-018-1437-9.

Lv, H., Zhang, Y., Sun, G., Bao, K., Gao, Y., Qi, X., Cui, H., Wang, Y., Li, K., Gao, L., Pan, Q., Wang, X. and Liu, C. 2017. Genetic evolution of Gallid herpesvirus 2 isolated in China. Infect. Genet. Evol. 51, 263-274.

Musa, U., Abdu, P.A., Salami-Shinaba, J.O., Sati, N.M., Kumbashi, P.R., Emenna, P.E., Odugbo, M.O., Mera, U.M. and Karsin, P.D. 2013. Causes of mortality in Japanese quails reared on deep litter in Vom, Nigeria. Res. J. Poult. Sci. 6, 73-78.

Nair, V. 2018. Spotlight on avian pathology: Marek's disease. Avian Pathol. 47(3), 440-442. 
Nair, V. and Fadly, A.M. 2013. Leukosis/sarcoma group. In Diseases of poultry, 13th ed. Eds., Saif, Y.M., Fadly, A.M., Glisson, J.R., McDougald, L.R., Nolan, L.K. and Swayne, D.E. Ames, IA: Blackwell Publishing, pp: 553-593.

Nawathe, D.R., Ojeh, C.K. and Onunkwo, O. 1978. Incidence of Marek's disease in Northern states of Nigeria. Vet. Rec. 102, 128.

Olabode, H.O.K., Jwander, L.D., Moses, G.D., Ighodalo, E. and Ebaidomeh, S.A. 2009. Prevalence of avian leukosis and Marek's disease in Ilorin, Kwara State, Nigeria. Nig. Vet. J. 30(3), 64-68.

Payne, L.N. 2004. Pathological responses to infection. In Marek's disease: an evolving problem. Elsevier Academic Press, London, UK pp: 78-97.

Pandey, U., Bell, A.S., Renner, D.W., Kennedy, D.A., Shreve, J.T., Cairns, C.L., Jones, M.J., Dunn, P.A., Read, A.F. and Szpara, M.L. 2016. DNA from dust: comparative genomics of large DNA viruses in field surveillance samples. mSphere 1(5), pii: e00132-16; doi:10.1128/mSphere.00132-16.

Pastoret, L.N. 2004. Introduction. In Marek's disease: an evolving problem. Elsevier Academic Press, London, UK pp: 1-7.

Pradhan, H.K., Mohanty, G.C. and Mukit, A. 1985. Marek's disease in Japanese quails (Coturnix coturnix japonica): a study of natural cases. Avian Dis. 29, 575-582.

Ralapanawe, S., Renz, K.G., Burgess, S.K. and Walkden-Brown, S.W. 2016. Field studies of the detection, persistence and spread of the Rispens CVI988 vaccine virus and the extent of co-infection with Marek's disease virus. Aust. Vet. J. 94(9), 329337.

Read, A.F., Baigent, S.J., Powers, C., Kgosana, L.B., Blackwell, L., Smith, L.P., Kennedy, D.A., Walkden-Brown, S.W. and Nair, V.K. 2015. Imperfect vaccination can enhance the transmission of highly virulent pathogens. PLoS Biol. 13(7), e1002198. doi:10.1371/journal.pbio.1002198.

Reddy, S.M., Izumiya, Y. and Lupiani, B. 2017. Marek’s disease vaccines: current status, and strategies for improvement and development of vector vaccines. Vet. Microbiol. 206, 113-120.

Renz, K.G., Cheetham, B.F. and Walkden-Brown, S.W. 2013. Differentiation between pathogenic serotype 1 isolates of Marek's disease virus and the Rispens CVI988 vaccine in Australia using real-time PCR and high resolution melt curve analysis. J. Virol. Methods 187, 144-152.

Sani, N.A., Aliyu, H.B., Musa, I.W., Wakawa, A.M., Abalaka, S.E., Oladele, S.B., Sa'idu, L. and Abdu, P.A. 2017. A nine-year retrospective study of avian neoplastic diseases in Zaria, Kaduna state, Nigeria. Sokoto J. Vet. Sci. 15(1), 36-41.

Schat, K.A. 2016. History of the first-generation Marek's disease vaccines: the science and littleknown facts. Avian Dis. 60, 715-724.

Schat, K.A. and Nair, V. 2013. Neoplastic diseases: Marek's disease. In Diseases of poultry, 13th ed. Eds., Swayne, D.E., Glisson, J.R., McDougald, L.R., Nolan, L.K., Suarez, D.L. and Nair, V.L. Hoboken, NJ: Wiley-Blackwell, pp: 515-552.

Schock, A., Garcia-Rueda, C., Byas, R., Nuñez, A. and Baigent, S. 2016. Severe outbreak of Marek's disease in crested partridges (Rollulus rouloul). Vet. Rec. 179, 443-444.

Wakawa, A.M., Muhammad, Z.K., Aliyu, H.B. and Mohammed, B. 2012. A retrospective analysis of Marek's disease diagnosed at Poultry Clinic of Ahmadu Bello University, Zaria, Nigeria. J. Vet. Adv. 2(8), 424-429.

Wozniakowski, G., Samorek-Salamonowicz, E. and Kozdrun, W. 2011. Rapid detection of Marek's disease virus in feather follicles by loop-mediated isothermal amplification. Avian Dis. 55, 462-467.

Zavala, G. 2013. Virus-induced Immunosuppression: Reticuloendotheliosis virus and other Immmunosuppressiveviruses. InImmunosuppresive diseases of poultry. Ed., Gimeno, I.M. Zaragoza, Spain: Servet-Group Asis, pp: 156-172.

Zelnik, V. 2004. Diagnosis of Marek's disease. In Marek's disease: an evolving problem. Elsevier Academic Press, London, UK pp: 156-167. 